\title{
Formulation of a new finite element based on assumed strains for membrane structures
}

\author{
Lahcene Fortas $^{1} \cdot$ Lamine Belounar $^{1} \cdot$ Tarek Merzouki $^{2}$ \\ Received: 8 August 2019 / Accepted: 4 November 2019 / Published online: 16 November 2019 \\ (c) The Author(s) 2019
}

\begin{abstract}
In this paper, a new triangular membrane finite element with in-plane drilling rotation has been developed using the strainbased approach for static and free vibration analyses. The proposed element, having three degrees of freedom at each of the three corner nodes, is based on assumed strain functions satisfying both compatibility and equilibrium equations. Numerical investigations have been conducted using several tests, including static and free vibration problems, and the obtained results are compared with analytical and numerical available solutions. It is found that efficient convergence characteristics and accurate results can be achieved using the developed element.
\end{abstract}

Keywords Strain approach · Drilling rotation · Static analysis · Free vibration analysis

$\begin{array}{ll}\text { List of symbols } \\ \rho & \text { Material density } \\ \nu & \text { Poisson's ratio } \\ E & \text { Young's modulus } \\ H & \text { Thickness of plate } \\ \Omega & \text { Angular frequency } \\ \varepsilon_{x}, \varepsilon_{y} & \text { Normal strains } \\ \gamma_{x y} & \text { Shear strain } \\ \sigma_{x}, \sigma_{y} & \text { Normal stresses } \\ \tau_{x y} & \text { Shear stress } \\ u, v & \text { Translations in the } x \text { - and } y \text {-directions, } \\ & \text { respectively } \\ \theta & \text { In-plane rotation (about } z \text {-axes) } \\ x, y & \text { Co-ordinates system } \\ {\left[K^{e}\right]} & \text { Element stiffness matrix } \\ {\left[M^{e}\right]} & \text { Element mass matrix } \\ {[K]} & \text { Structural stiffness matrix } \\ {[M]} & \text { Structural mass matrix }\end{array}$

Lahcene Fortas

fortas.lahcene@gmail.com

Lamine Belounar

belounarl@yahoo.com

Tarek Merzouki

tarek.merzouki@uvsq.fr

1 MN2I2S Laboratory, Faculty of Science and Technology, Biskra University, Biskra, Algeria

2 Laboratoire d'Ingénierie des Systèmes de Versailles, Vélizy, France
[A] Transformation matrix

[N] Displacement matrix

$[Q] \quad$ Strain matrix

[D] Elasticity matrix

$\{F\} \quad$ Structural nodal forces' vector

$\{q\} \quad$ Structural nodal displacements' vector

$\left\{q_{e}\right\} \quad$ Element nodal displacements' vector

\section{Introduction}

The formulation of simple and robust finite elements has become one of the most important research fields in structural mechanics. However, membrane displacement-based elements such as the four-node quadrilateral element behave very poorly for such case of bending problems. Considerable efforts have been oriented to overcome the weaknesses of these elements by the development of efficient elements using different concepts and formulations such as the assumed strain or enhanced assumed strain elements ( $\mathrm{Li}$ and Huang 2014; Piltner and Taylor 1999), the generalized conforming elements (Chen et al. 2004; Li and Huang 2014), the quasi-conforming elements (Wang et al. 2014; Xia et al. 2017), and the quadrilateral area coordinate elements ( $\mathrm{Li}$ and Huang 2014; Cen et al. 2015). Other robust membrane elements with in-plane rotation (Kugler et al. 2010; Cen et al. 2011; Zouari et al. 2016) have been developed.

The strain-based approach has largely attracted the attention of its researchers for the development of new finite elements with high accuracy. Unlike the classical displacement 
model, direct integration of the imposed strains field allows to obtain the displacements field. The main feature of this approach is that the resulting components of displacement can be enriched by higher order terms without the need of introducing non-essential degrees of freedom. This can lead to have elements with better accuracy on displacements, strains, and stresses. Also, a faster convergence of results for these elements is obtained when compared with the corresponding displacement elements having the same degrees of freedom.

The strain approach has been applied by many developers to construct robust and efficient finite elements. It was first used by Ashwell et al. (1971) for the case of curved problems. Afterward, this approach was introduced to plane elasticity (Sabir 1985a; Belarbi and Maalam 2005; Rebiai and Belounar 2013, 2014), and then extended for threedimensional elasticity problems (Belarbi and Charif 1999; Belounar and Guerraiche 2014; Guerraiche et al. 2018; Messai et al. 2019),for plate bending (Belounar and Guenfoud 2005; Himeur and Guenfoud, 2011; Belounar et al. 2018, 2019), and as well as for shell structures (Sabir and Lock 1972; Assan 1999; Djoudi and Bahai 2003, 2004a, b; Sabir and Moussa 1996, 1997).

In the goal of the development of a $2 \mathrm{D}$ element that is more efficient than the Q4 element, a new three-node triangular membrane element with drilling rotation has been formulated using the strain approach for static and free vibration analyses. This element named "SBTDR" (strain-based triangular with drilling rotation) possesses three degrees of freedom at each node, two translations $(U, V)$ and one inplane rotation $(\theta z)$. It has first been tested for static and then for free vibration analysis through several examples. The numerical results obtained show the good accuracy and efficiency of the present element.

\section{Formulation of the developed element}

The strain-displacement relations of an element for plan elasticity in the Cartesian coordinate system (Fig. 1) can be written as:

$$
\begin{aligned}
& \varepsilon_{x}=\frac{\partial U}{\partial x} \\
& \varepsilon_{y}=\frac{\partial V}{\partial y} \\
& \gamma_{x y}=\frac{\partial U}{\partial y}+\frac{\partial V}{\partial x} .
\end{aligned}
$$

The strain components given by Eq. (1) must satisfy the following compatibility equation:

$$
\frac{\partial^{2} \varepsilon_{x}}{\partial y^{2}}+\frac{\partial^{2} \varepsilon_{y}}{\partial x^{2}}-\frac{\partial^{2} \gamma_{x y}}{\partial x \partial y}=0 .
$$

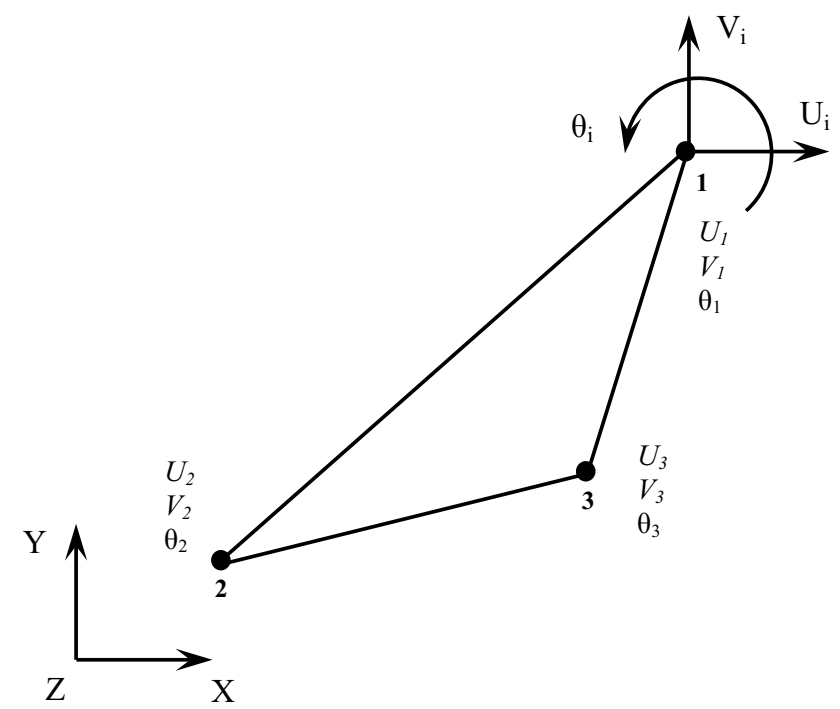

Fig. 1 Three-node triangular membrane strain-based element (SBTDR)

The triangular element has three degrees of freedom at each of the three corner nodes, corresponding to two translations $(U, V)$ and one in-plane rotation $\left(\theta_{z}\right)$. Therefore, the displacement functions should contain nine independent constants. First, the resulting displacement field of the rigid body modes is obtained by equating the three strains given in Eq. (1) to zero, and after integration, the following can be obtained:

$U=a_{1}-a_{3} y$
$V=a_{2}+a_{3} x$
$\theta=a_{3}$.

Since the three constants $\left(a_{1}, a_{2}\right.$, and $\left.a_{3}\right)$ are taken for representing the displacements field of the rigid body modes, as shown in Eq. (3), the remaining six constants $\left(a_{4}, a_{5}, \ldots, a_{9}\right)$ are used to express the imposed strains of the element apportioned as:

$$
\begin{aligned}
\varepsilon_{x} & =a_{4}+a_{5} y-a_{7} v x-a_{9} \frac{(1-v)}{(1+v)} x y \\
\varepsilon_{y} & =-a_{5} v y+a_{6}+a_{7} x-a_{9} \frac{(1-v)}{(1+v)} y x \\
\gamma_{x y} & =a_{8}+a_{9}\left(x^{2}+y^{2}\right) .
\end{aligned}
$$

The above strain functions of the current element given by Eq. (4) satisfy both the compatibility equation [Eq. (2)] and the equilibrium equations (Eqs. (5) and (6)), where $v$ is the Poisson's ratio:

$\frac{\partial \sigma_{x}}{\partial x}+\frac{\partial \tau_{x y}}{\partial y}=0$ 
$\frac{\partial \sigma_{y}}{\partial y}+\frac{\partial \tau_{x y}}{\partial x}=0$

The assumed strains of Eq. (4) are substituted into Eq. (1), and after integration, the obtained displacements are:

$U=a_{4} x+a_{5} x y-a_{7}\left(v x^{2}+y^{2}\right) / 2+a_{8} y / 2-a_{9}\left(-\frac{R}{2} x^{2} y+\frac{R}{6} y^{3}-\frac{y^{3}}{3}\right)$

$V=-a_{5}\left(v y^{2}+x^{2}\right) / 2+a_{6} y+a_{7} x y+a_{8} x / 2-a_{9}\left(-\frac{R}{2} y^{2} x+\frac{R}{6} x^{3}-\frac{x^{3}}{3}\right)$

$\theta=-a_{5} x+a_{7} y+a_{9}\left(\left(x^{2}-y^{2}\right) k\right)$.

where:

$R=\frac{(1-v)}{(1+v)} ; k=\frac{v}{(1+v)}$.

The obtention of the final displacement field for the present element is given by summing Eqs. (3) and (7) to have:

$$
\begin{aligned}
& U=a_{1}-a_{3} y+a_{4} x+a_{5} x y-a_{7}\left(v x^{2}+y^{2}\right) / 2 \\
& +a_{8} y / 2-a_{9}\left(-\frac{R}{2} x^{2} y+\frac{R}{6} y^{3}-\frac{y^{3}}{3}\right) \\
& V=a_{2}+a_{3} x-a_{5}\left(v y^{2}+x^{2}\right) / 2+a_{6} y+a_{7} x y+a_{8} x / 2 \\
& -a_{9}\left(-\frac{R}{2} y^{2} x+\frac{R}{6} x^{3}-\frac{x^{3}}{3}\right) \\
& \theta=a_{3}-a_{5} x+a_{7} y+a_{9}\left(\left(x^{2}-y^{2}\right) k\right) \text {. }
\end{aligned}
$$

The displacement field given above [Eq. (8] satisfies both compatibility [Eq. (2)] and equilibrium [Eqs. (5), (6)]. These displacement functions given by Eq. (8) and the strain functions of Eq. (4) can be, respectively, written in matrix form as:

$$
\begin{aligned}
& \left\{U_{e}\right\}=\left\{\begin{array}{c}
U \\
V \\
\theta
\end{array}\right\}=[N]\{a\}, \\
& \{\varepsilon\}=\left\{\begin{array}{c}
\varepsilon_{x} \\
\varepsilon_{y} \\
\gamma_{x y}
\end{array}\right\}=[Q]\{a\} .
\end{aligned}
$$

With $\{a\}=\left\{a_{1}, a_{2}, \ldots \ldots \ldots, a_{9}\right\}^{T}$ :
The stress-strain relationship is given by:

$\{\sigma\}=[D]\{\varepsilon\}$.

For static and free vibration, the standard weak form can, respectively, be expressed as:

$$
\begin{aligned}
& \int_{V^{e}} \delta\{\varepsilon\}^{T}\{\sigma\} d V=\int_{V^{e}} \delta\left\{U_{e}\right\}^{T}\left\{f_{v}\right\} d V, \\
& \int_{V^{e}} \delta\{\varepsilon\}^{T}\{\sigma\} d V+\int_{V^{e}} \delta\left\{U_{e}\right\}^{T}\left\{\ddot{U}_{e}\right\} d V=0 .
\end{aligned}
$$

Equations (9), (10), and (11) are substituted into Eqs. (12) and (13); we obtain:

$\delta\left\{q_{e}\right\}^{T}\left(\int_{V^{e}}[B]^{T}[D][B] d V\right)\left\{q_{e}\right\}=\delta\left\{q_{e}\right\}^{T}\left(\int_{V^{e}}[P]^{T}\left\{f_{v}\right\} d V\right)$,

$\delta\left\{q_{e}\right\}^{T}\left(\int_{V^{e}}[B]^{T}[D][B] d V\right)\left\{q_{e}\right\}+\delta\left\{q_{e}\right\}^{T}\left(\int_{V^{e}} \rho[P]^{T}[P] d V\right)\left\{\ddot{q}_{e}\right\}=0$,

where the element stiffness and mass matrices are, respectively, given as:

$\left[K_{e}\right]=\int_{V^{e}}[B]^{T}[D][B] d V=[A]^{-T}\left(\int_{V^{e}}[Q]^{T}[D][Q] d V\right)[A]^{-1}$,

$\left[M_{e}\right]=\int_{V^{e}} \rho[P]^{T}[P] d V=[A]^{-T}\left(\int_{V^{e}} \rho[N]^{T}[N] d V\right)[A]^{-1}$,

where $[A]$ is a matrix relating to the nine nodal element displacements to the nine constants $\left(a_{1}, a_{2}-a_{9}\right)$, and it is given in the "Appendix 1" with the matrices $[B],[P]$, and $[D]$.

The global equilibrium equation for the static domain is written as:

$[N]=\left[\begin{array}{ccccccccc}1 & 0 & -y & x & x y & 0 & -\left(v x^{2}+y^{2}\right) / 2 & y / 2 & -\left(-\frac{R}{2} x^{2} y+\frac{R}{6} y^{3}-\frac{y^{3}}{3}\right) \\ 0 & 1 & x & 0 & -\left(v y^{2}+x^{2}\right) / 2 & y & x y & x / 2 & -\left(-\frac{R}{2} y^{2} x+\frac{R}{6} x^{3}-\frac{x^{3}}{3}\right) \\ 0 & 0 & 1 & 0 & -x & 0 & y & 0 & \left(x^{2}-y^{2}\right) k\end{array}\right]$,

$[Q]=\left[\begin{array}{ccccccccc}0 & 0 & 0 & 1 & y & 0 & -v x & 0 & -\frac{(1-v)}{(1+v)} x y \\ 0 & 0 & 0 & 0 & -v y & 1 & x & 0 & -\frac{(1-v)}{(1+v)} y x \\ 0 & 0 & 0 & 0 & 0 & 0 & 0 & 1 & \left(x^{2}+y^{2}\right)\end{array}\right]$.

$[K]\{q\}=[F]$.

The global equilibrium equation for the free vibration domain is written as: 
$[K]-\omega^{2}[M]\{q\}=0$,

where $\{q\}$ is the structural global displacements vector, $[K]$ and $[M]$ are the structural stiffness and mass matrices, and $\{F\}$ is the global load vector. These are obtained by assembling the individual element contributions using the elementary matrices $\left[K_{e}\right]$ and $\left[M_{e}\right]$.

All elements with their references used in the article are given in "Appendix 2".

\section{Static validation}

\section{Linear Mac-Neal beam}

In this test, the slender Mac-Neal beam (MacNeal and Harder 1985) is used to evaluate the efficiency of the developed element, where the geometrical and the material characteristics are given in Fig. 2. The obtained results presented in Table 1 show that the developed element is insensitive to mesh distortion and its results are in good agreement with the exact solution. Besides, it should be noted that the developed element is more accurate than the strain-based element (SBTIEIR) in both load cases.

\section{Cook's membrane problem}

The clamped trapezoidal plate, known as Cook's membrane benchmark test (Cook 1974), is analyzed for a uniformly distributed shear load $(F=1)$ applied at the free end. The geometrical and material properties are presented in Fig. 3 and the results of the displacement at the free end (point C) are given in Table 2. The results of the SBTDR element are found to be slightly better than those obtained using the other elements. It can be noted that good accuracy is provided for the current element regardless of mesh density.

\section{Thick circular beam under in-plane shear load}

The test shown in Fig. 4 concerns the thick circular beam subjected to a shear force $F=600$ at its free end. Four regular meshes of $2 \times 2,4 \times 2$, and $6 \times 2$ plane stress triangular elements for this curved beam are considered. The obtained results of the vertical displacement at point $\mathrm{A}$ are given in

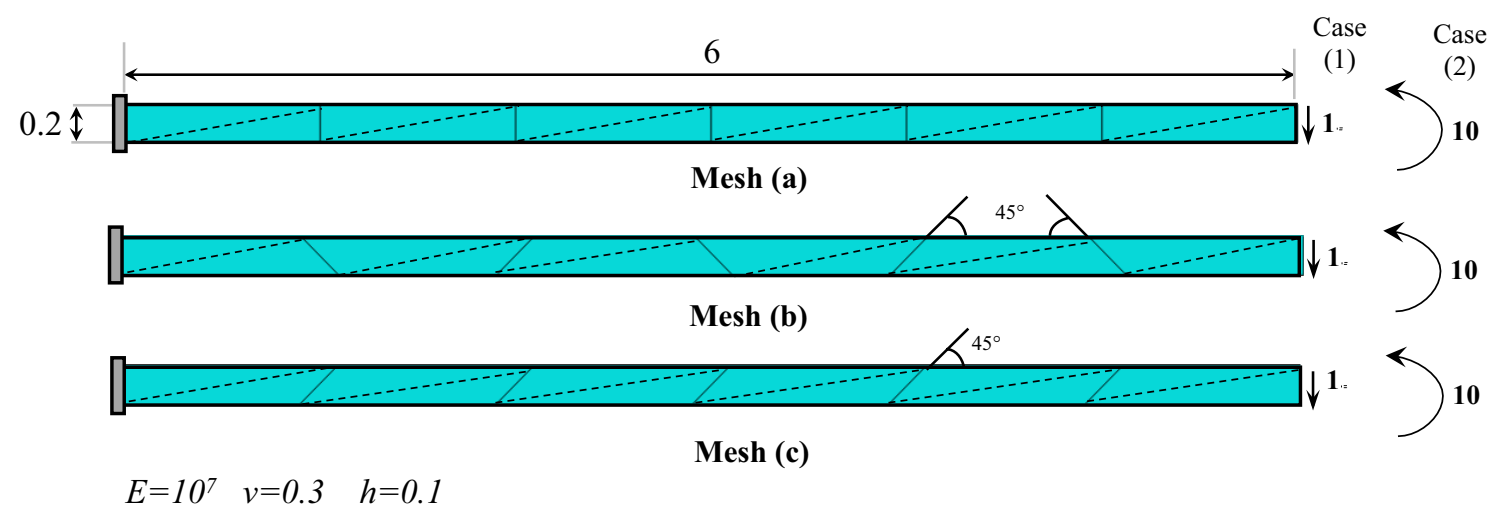

Fig. 2 Mac-Neal's elongated beam subjected to end shear (1) and end bending (2)

Table 1 Normalized deflection at free end for Mac-Neal's elongated beam subjected to end shear and bending

\begin{tabular}{|c|c|c|c|c|c|c|}
\hline \multirow[t]{2}{*}{ Element } & \multicolumn{3}{|l|}{ End bending } & \multicolumn{3}{|l|}{ End shear } \\
\hline & $\operatorname{Mesh}(a)$ & Mesh $(b)$ & $\operatorname{Mesh}(c)$ & $\operatorname{Mesh}(a)$ & $\operatorname{Mesh}(b)$ & $\operatorname{Mesh}(c)$ \\
\hline Q4 & 0.093 & 0.022 & 0.031 & 0.093 & 0.027 & 0.034 \\
\hline PS5 $\beta$ & 1.000 & 0.046 & 0.726 & 0.993 & 0.052 & 0.632 \\
\hline AQ & 0.910 & 0.817 & 0.881 & 0.904 & 0.806 & 0.873 \\
\hline MAQ & 0.910 & 0.886 & 0.890 & 0.904 & 0.872 & 0.884 \\
\hline Q4S & - & - & - & 0.993 & 0.986 & 0.988 \\
\hline $07 \beta$ & 1.000 & 0.998 & 0.992 & 0.993 & 0.988 & 0.985 \\
\hline SBTIEIR & 0.437 & 0.015 & 0.374 & 0.435 & 0.005 & 0.333 \\
\hline SBTDR & 1.000 & 1.000 & 1.000 & 0.992 & 0.904 & 0.888 \\
\hline $\begin{array}{l}\text { Beamtheory (Mac- } \\
\text { Neal and Harder } \\
\text { 1985) }\end{array}$ & $1.000(0.270)$ & & & $1.000(0.1081)$ & & \\
\hline
\end{tabular}




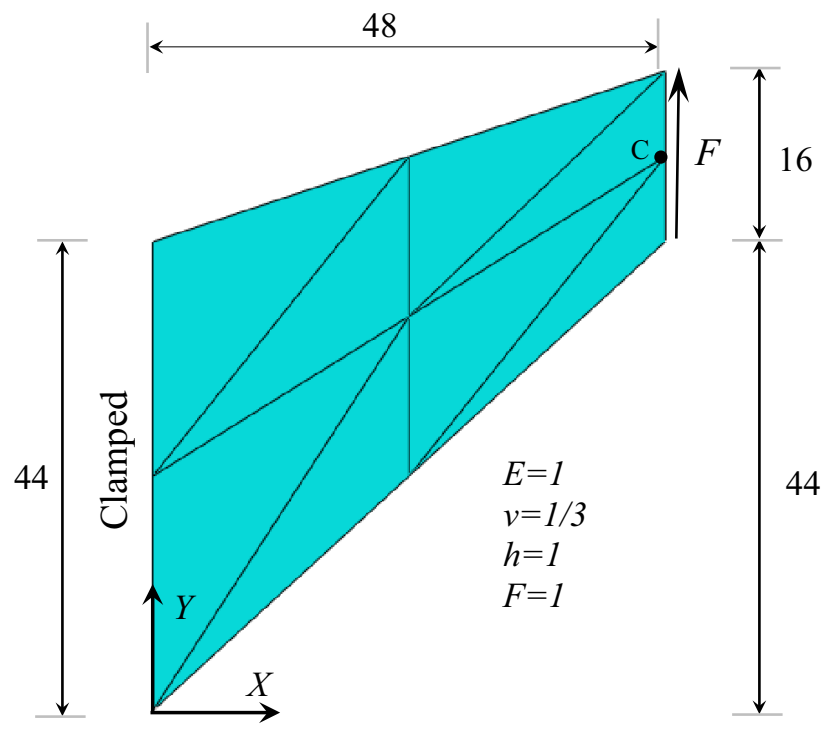

Fig. 3 Cook's plate modeled with eight triangular elements

Table 3 and compared with those of other elements, showing that the developed element provides more accurate results than the CPS4 quadratic element and less accurate than the QACM4 one.

\section{Shear wall with openings}

A shear wall structure with openings (Fig. 5) has been analyzed to determine the efficiency and the accuracy of the SBTDR element. The geometrical and material properties of this eight-story coupled shear wall are illustrated in Fig. 5. The lateral displacements of the model at story 2, 4, 6, and 8 (Table 4) have been computed and compared with those of commercial codes (SAP-2000, STAADPRO) given by (Paknahad et al. 2007). The obtained results using the developed SBTDR element are in a good agreement with those obtained using the OPT element and commercial software SAP-2000, STAADPRO.

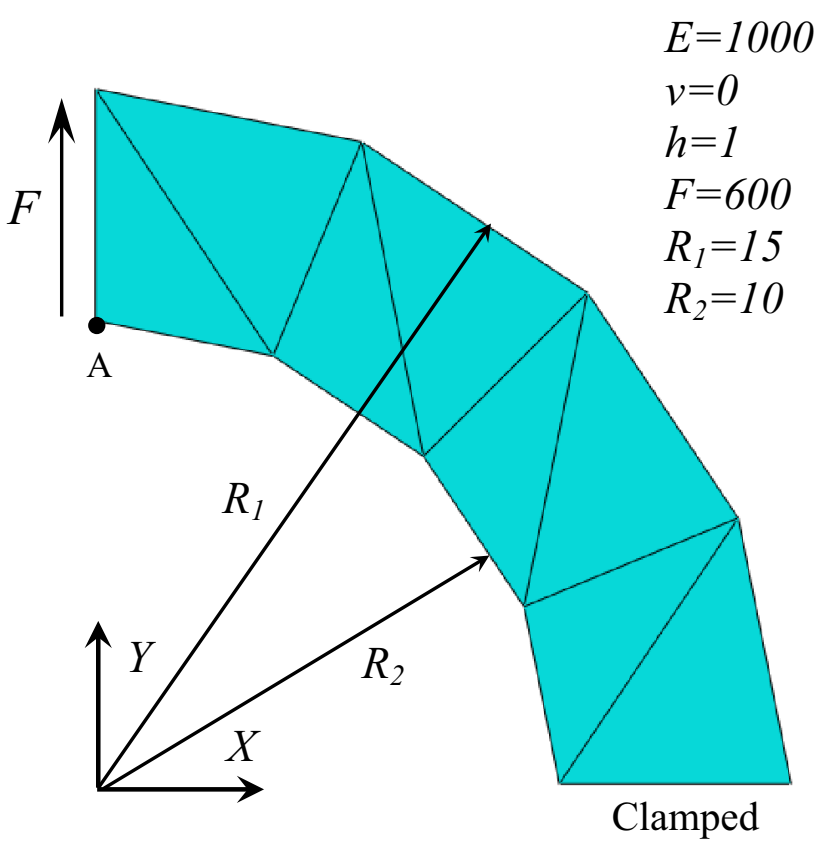

Fig. 4 Thick circular beam modeled with eight triangular elements

\section{Thin-circular beam under in-plane shear load}

This test allows analyzing a thin-circular beam clamped at one end and subjected to a unit shear load at the free end (Fig. 6). Three regular meshes of $6 \times 1,12 \times 2$, and $24 \times 4$ plane stress triangular elements are considered. The obtained results of the vertical displacement at the free end (point A) are given in Table 5. It should be noted that the SBTDR element offers a better convergence towards the exact solution when compared with other elements.

\section{Dynamic numerical validation}

Three problems are presented to demonstrate the robustness and the accuracy of the current element for free vibration analysis.
Table 2 Normalized displacement at the free end for tapered panel under end shear

\begin{tabular}{lllll}
\hline Element model & $\begin{array}{l}2 \times 2 \text { mesh } \\
\text { Vertical displacement }\end{array}$ & $\begin{array}{l}4 \times 4 \text { mesh } \\
\text { Vertical displacement }\end{array}$ & $\begin{array}{l}8 \times 8 \text { mesh } \\
\text { Vertical displacement }\end{array}$ & $\begin{array}{l}\text { Error (\%) } \\
(8 \times 8)\end{array}$ \\
\hline HTD & 0.847 & 0.951 & 0.985 & 1.5 \\
HT & 0.502 & 0.765 & 0.921 & 7.9 \\
MEAS & 0.502 & 0.765 & 0.921 & 7.9 \\
ALLMAN & 0.823 & 0.938 & 0.981 & 1.9 \\
TE4 & 0.848 & 0.941 & - & - \\
SBTDR & 0.663 & 0.877 & 1.069 & 6.9 \\
$\begin{array}{c}\text { Bergan and Felippa } \\
(1985)(32 \times 32)\end{array}$ & & $1.000(23.90)$ & & \\
\hline
\end{tabular}


Table 3 Normalized vertical displacement at point A

\begin{tabular}{lllll}
\hline Mesh & HS-A7 & QACM4 & CPS4 & SBTDR \\
\hline $2 \times 1$ & 0.987 & - & 0.251 & 0.322 \\
$4 \times 1$ & 0.994 & 0.938 & 0.643 & 0.766 \\
$6 \times 1$ & - & 0.979 & 0.811 & 0.937 \\
Error $(\%)(6 \times 1)$ & - & 2.1 & 18.9 & 6.3 \\
Reference solution & 90.1 & & & \\
$\quad$ (Zouari et al. 2016) & & & & \\
\hline
\end{tabular}

\section{In-plane free vibration problem of a cantilever shear wall}

The free vibration problem for in-plane of a cantilever shear wall, studied by Cheung (Cheung et al. 2000), is considered by taking the first three natural frequencies of the flexural modes. The geometrical and material properties are presented in Fig. 7, and the natural frequencies of the SBTDR element are calculated and compared with those obtained by other elements, as given in Table 6 . The results obtained by the SBTDR element are less accurate than those obtained by the element $\mathrm{T} 6$, whereas the frequencies obtained by the elements Q4 and T3 are considerably higher than those of the analytical solution.

\section{Free vibration analysis of a cantilever beam}

This analysis has been performed in the case of a plane stress problem of a cantilever beam, with its characteristics given in Fig. 8. The numerical results of the first four frequencies for the SBTDR element (Table 7) have been compared with those of several elements (SFEM,
Table 4 Comparison of the lateral deflection at different story levels

\begin{tabular}{lllll}
\hline Floor & 2 & 4 & 6 & 8 \\
\hline SAP 2000 & 0.55 & 1.48 & 2.54 & 3.62 \\
STAAD-PRO & 0.68 & 1.68 & 2.78 & 3.86 \\
OPT element & 0.71 & 1.91 & 3.19 & 4.43 \\
SBTDR & 0.62 & 1.72 & 2.89 & 4.017 \\
\hline
\end{tabular}

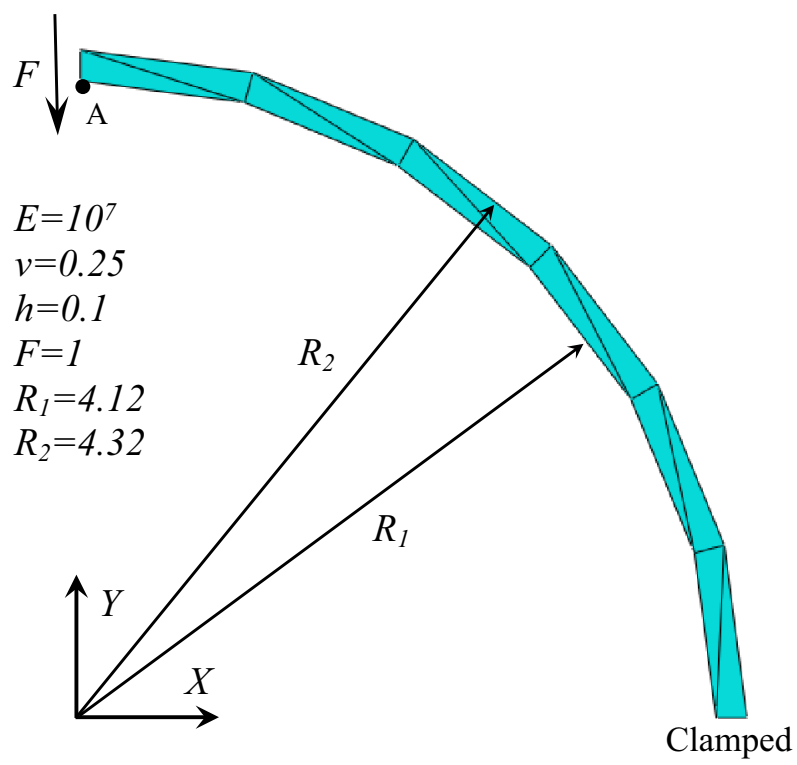

Fig. 6 Thin circular beam modeled with 12 triangular elements
Fig. 5 Geometrical and material properties of coupled shear wall
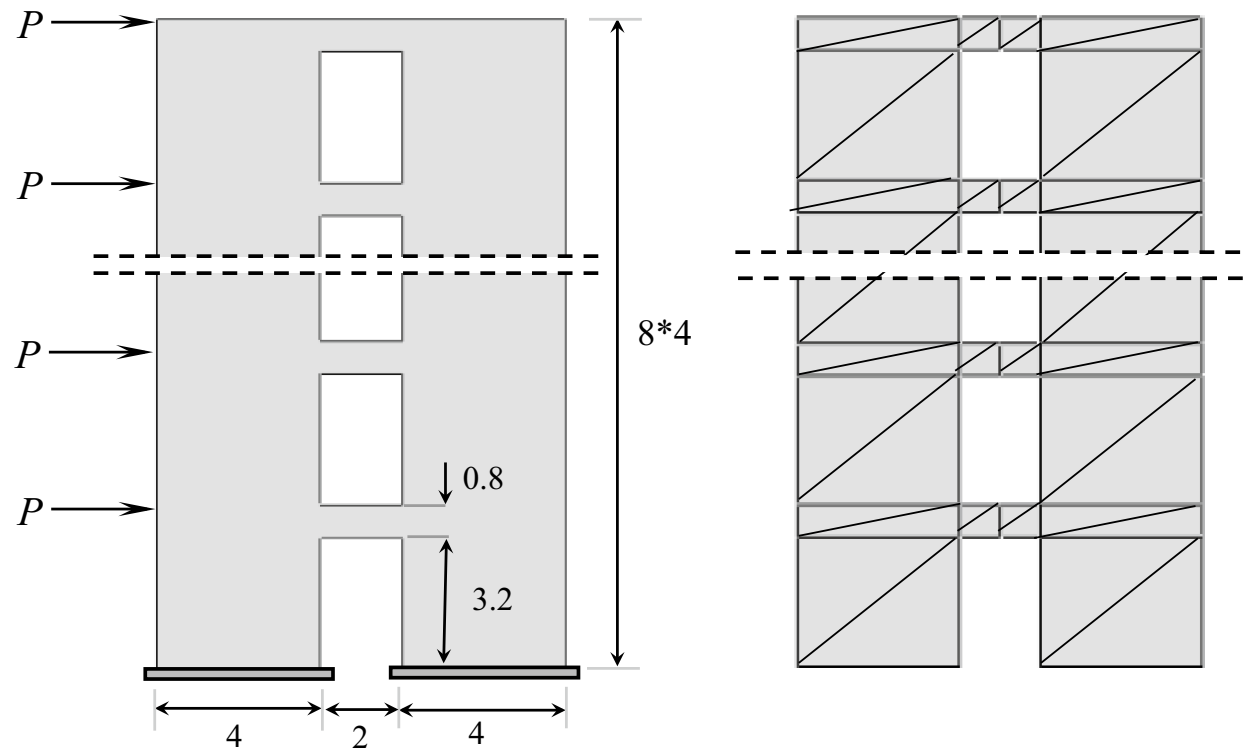

$E_{c}=2 E+7 \mathrm{KN} / \mathrm{m}^{2} ; v=0.25 ; h=0.4 \mathrm{~m} ; P=500 \mathrm{KN}$ 
Table 5 Normalized vertical displacement at the free end

\begin{tabular}{lccc}
\hline Mesh & CPS4 & HT & SBTDR \\
\hline $6 \times 1$ & 0.073 & 0.075 & 0.2025 \\
$12 \times 2$ & 0.247 & 0.251 & 0.454 \\
$24 \times 4$ & 0.572 & 0.555 & 0.797 \\
Error (\%) $(24 \times 4)$ & 42.8 & 44.5 & 20.3 \\
$\begin{array}{l}\text { Reference solution (Choo } \\
\text { et al. 2006) }\end{array}$ & 0.08734 & & \\
\hline
\end{tabular}

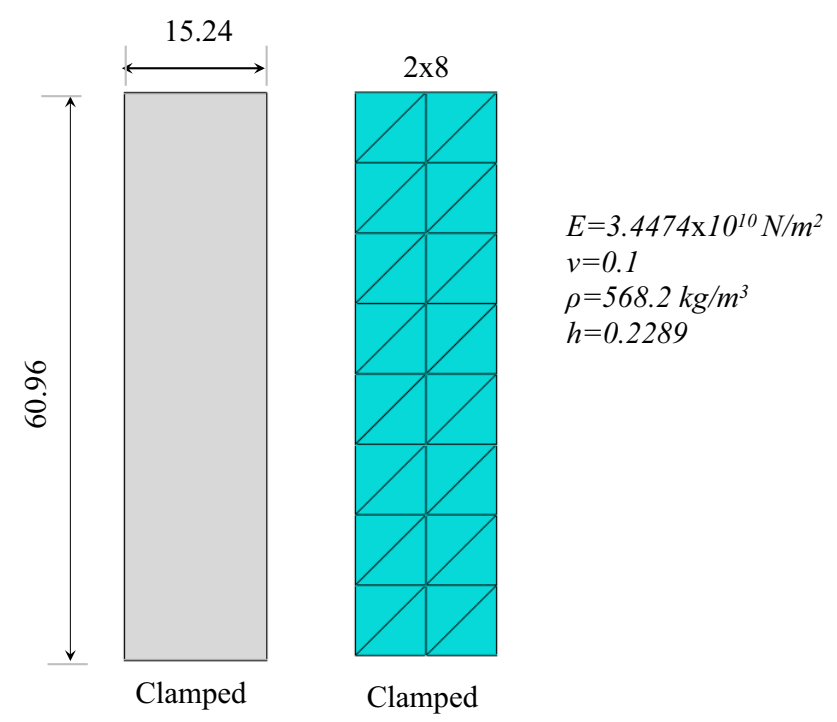

Fig. 7 Geometry and mesh discretization of a cantilever shear wall

Table 6 First three frequencies $(\mathrm{Hz})$ of the flexural modes of a cantilever shear wall

\begin{tabular}{llll}
\hline Mode & 1 & 2 & 3 \\
\hline Q4 & 5.252 & 28.028 & 67.652 \\
T3 & 6.658 & 33.759 & 79.341 \\
T6 & 4.959 & 25.772 & 60.221 \\
SBTDR & 4.31 & 24.11 & 60.50 \\
Theoretical value (Cheung & 4.973 & 26.391 & 62.066 \\
et al. 2000) & & & \\
\hline
\end{tabular}

FEM T3, and Q4) to examine the accuracy of the present element. A much better convergence of the results is achieved with the element SFEM and the element SBTDR offers better results than that when using T3 or Q4 elements, with an appreciable accuracy compared to the reference solution.

\section{Free vibration of a cantilever beam with variable cross section}

In this test, a cantilever beam with variable cross section is studied, for which geometry and mesh are presented in Fig. $9\left(L=10 ; H(0)=5, H(L)=3, t=1.0, E=3.0 \times 10^{7}\right.$, $v=0.3$, and $\rho=1.0$.). The computed results of the first four natural frequencies using the SBTDR element are given in Table 8 . Indeed, the obtained results of the SBTDR element are less accurate than those of the fournode QBI element and it behaves much less than eightnode Q9 and SFEM elements.

\section{Conclusion}

In the current paper, a three-node triangular membrane finite element with in-plane drilling rotation has been studied using the strain approach for both linear static and free vibration analyses. The developed element (SBTDR) has three degrees of freedom at each corner node where its displacements field contains higher polynomial terms and satisfies the compatibility equations as well as the equilibrium equations as additional conditions. According to the tested problems, the obtained numerical results show a high degree of accuracy and achieve a rapid convergence to analytical solutions with relatively coarse meshes. This element provides satisfactory results compared to other robust elements given in the literature. 
Fig. 8 Meshes of the cantilever beam

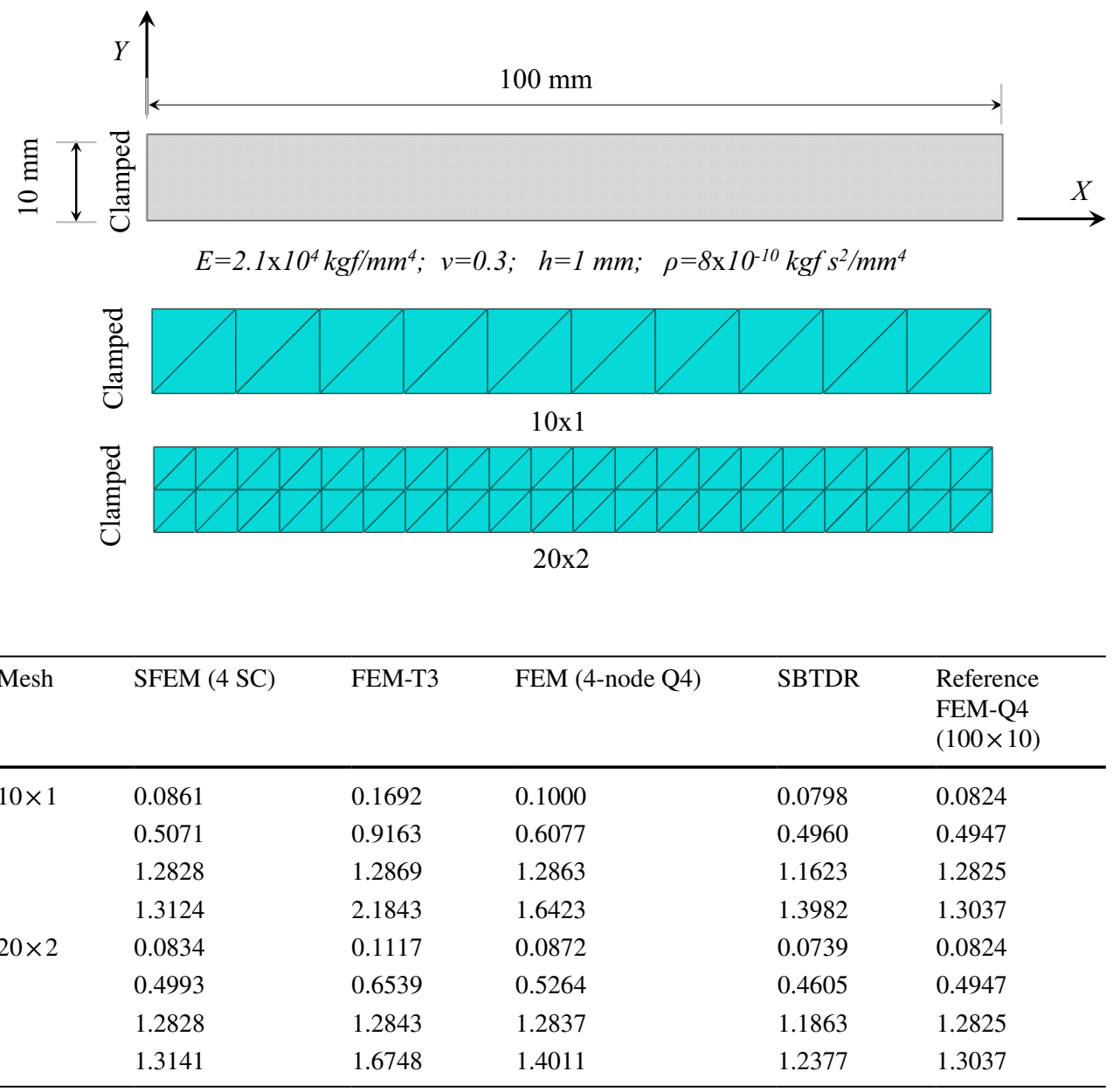

Table 7 First four natural frequencies $\left(\times 10^{4} \mathrm{~Hz}\right)$
Table 8 First four natural frequencies $\left(\times 10^{4} \mathrm{~Hz}\right)$ of a variable crosssection cantilever beam

\begin{tabular}{lllll}
\hline SFEM (4 SC) & $\begin{array}{l}\text { FEM (4-node } \\
\text { Q4) }\end{array}$ & $\begin{array}{l}\text { FEM (8-node } \\
\text { Q9) }\end{array}$ & $\begin{array}{l}\text { FEM } \\
\text { (4-node } \\
\text { QBI) }\end{array}$ & SBTDR \\
\hline 0.4156 & 0.4219 & 0.4167 & 0.4149 & 0.4054 \\
1.4572 & 1.5102 & 1.4623 & 1.4540 & 1.4348 \\
1.5140 & 1.5183 & 1.5155 & 1.5137 & 1.4793 \\
2.9119 & 3.1156 & 2.9534 & 2.9031 & 2.8759 \\
\hline
\end{tabular}

\section{Compliance with ethical standards}

Conflict of interest The authors declare that they have no conflict of interest.

Open Access This article is distributed under the terms of the Creative Commons Attribution 4.0 International License (http://creat ivecommons.org/licenses/by/4.0/), which permits unrestricted use,

Fig. 9 A cantilever beam with a variable cross section and its mesh 
distribution, and reproduction in any medium, provided you give appropriate credit to the original author(s) and the source, provide a link to the Creative Commons license, and indicate if changes were made.

\section{Appendix 1}

The matrix $[A]$ with the dimension $(9 \times 9)$ for the SBTDR element relating to the nodal displacements vector $\left\{q_{e}\right\}$ and the constant parameters vector $\{a\}$ is obtained by applying Eq. (9) for each of the three-element node coordinates $\left(x_{i}\right.$, $\left.y_{i}\right),(i=1,2,3)$ as:

$\left\{q_{e}\right\}=[A]\{a\}$.

With $\left\{q_{e}\right\}=\left\{U_{1}, V_{1}, \theta_{1}, U_{2}, V_{2}, \theta_{2}, U_{3}, V_{3}, \theta_{3}\right\}^{T}$; and the transformation matrix $[A]$ is:

$[A]=\left[\begin{array}{l}N\left(x_{1}, y_{1}\right) \\ N\left(x_{2}, y_{2}\right) \\ N\left(x_{3}, y_{3}\right)\end{array}\right]$.

Using Eq. (20), the constant parameter vector $\{a\}$ can be obtained as:

$\{a\}=[A]^{-1}\left\{q_{e}\right\}$.

By substituting Eq. (22) into Eqs. (9) and (10), we obtain:

$\left\{U_{e}\right\}=[N][A]^{-1}\left\{q_{e}\right\}=[P]\left\{q_{e}\right\}$,

$\{\varepsilon\}=[Q(x, y)][A]^{-1}\left\{q_{e}\right\}=[B]\left\{q_{e}\right\}$.

With $[P]=[N][A]^{-1}$;

$[B]=[Q(x, y)][A]^{-1}$,

where the elasticity matrix $[D]$ is given below for plane stress and plane strain.

For the case of plane stress problems, the elasticity matrix $[D]$ is:

$[D]=\frac{E}{\left(1-v^{2}\right)}\left[\begin{array}{ccc}1 & v & 0 \\ v & 1 & 0 \\ 0 & 0 & \frac{1-v}{2}\end{array}\right]$.

For the case of plane strain problems, the elasticity matrix $[D]$ is:

$[D]=\frac{E}{(1+v)(1-2 v)}\left[\begin{array}{ccc}(1-v) & v & 0 \\ v & (1-v) & 0 \\ 0 & 0 & \frac{(1-2 v)}{2}\end{array}\right]$.

\section{Appendix 2}

Note on the elements to compare is given:

PS5 $\beta$ : (Pian and Sumihara 1984)

AQ: (Cook 1986)

MAQ: Hybrid finite element with rotational degrees of freedom (Yanus et al. 1989)

Q4S: (MacNeal and Harder 1988)

07ß: (Sze et al. 1992)

SBTIEIR: (Sabir 1985b)

HTD, HT, MEAS, and TE4: (Choo et al. 2006)

SFEM (4 SC), FEM (4-node Q4), FEM (8-node Q9), and FEM (4-node QBI): (Dai and Liu 2007)

ALLMAN: (Allman 1988)

QACM4: (Cen et al. 2007)

HS-A7: (Rezaiee-Pajand and Karkon 2013)

CPS4: (Zouari et al. 2016)

SAP 2000, STAAD-PRO, OPT: (Paknahad et al. 2007)

\section{References}

Allman DJ (1988) Evaluation of the constant strain triangle with drilling rotations. Int J Numer Methods Eng 26(12):2645-2655

Ashwell DG, Sabir AB, Roberts TM (1971) Further studies in application of curved finite elements to circular arches. Int J Mech Sci 13(6):507-517

Assan AE (1999) Analysis of multiple stiffened barrel shell structures by strain based finite elements. Thin Wall Struct 35(4):233-253

Belarbi MT, Charif A (1999) Développement d'un nouvel élément hexaédrique simple basé sur le modèle en déformation pour l'étude des plaques minces et épaisses. Revue européenne des éléments finis 8(2):135-157

Belarbi MT, Maalam T (2005) On improved rectangular finite element for plane linear elasticity analysis. Revue européenne des éléments finis 14(8):985-997

Belounar L, Guenfoud M (2005) A new rectangular finite element based on the strain approach for plate bending. Thin Wall Struct 43(1):47-63

Belounar L, Guerraiche K (2014) A new strain based brick element for plate bending. Alex Eng J 53(1):95-105

Belounar A, Benmebarek S, Belounar L (2018) Strain based triangular finite element for plate bending analysis. Mech Adv Mater Struct. https://doi.org/10.1080/15376494.2018.1488310

Belounar A, Benmebarek S, Houhou MN, Belounar L (2019) Static, free vibration, and buckling analysis of plates using strain-based Reissner-Mindlin elements. Int J Adv Struct Eng 11(2):211-230

Bergan PG, Felippa CA (1985) A triangular membrane element with rotational degrees of freedom. Comput Methods Appl Mech Eng 50(1):25-69

Cen S, Chen XM, Fu XR (2007) Quadrilateral membrane element family formulated by the quadrilateral area coordinate method. Comput Methods Appl Mech Eng 196(41-44):4337-4353

Cen S, Zhou MJ, Fu XR (2011) A 4-node hybrid stress-function (HSF) plane element with drilling degrees of freedom less sensitive to severe mesh distortions. Comput Struct 89(5-6):517-528

Cen S, Zhou PL, Li CF, Wu CJ (2015) An unsymmetric 4-node, 8-DOF plane membrane element perfectly breaking through MacNeal's theorem. Int J Numer Methods Eng 103(7):469-500 
Chen XM, Cen S, Long YQ, Yaob ZH (2004) Membrane elements insensitive to distortion using the quadrilateral area coordinate method. Comput Struct 82(1):35-54

Cheung YK, Zhang YX, Chen WJ (2000) A refined non-conforming plane quadrilateral element. Comput Struct 78(5):699-709

Choo YS, Choi N, Lee BC (2006) Quadrilateral and triangular plane elements with rotational degrees of freedom based on the hybrid Trefftz method. Finite Elem Anal Des 42(11):1002-1008

Cook RD (1974) Improved two-dimensional finite element. J Struct Div 100(9):1851-1963

Cook RD (1986) On the Allman triangle and a related quadrilateral element. Comput Struct 22(6):1065-1067

Dai KY, Liu GR (2007) Free and forced vibration analysis using the smoothed finite element method (SFEM). J Sound Vib 301(3-5):803-820

Djoudi MS, Bahai H (2003) A shallow shell finite element for the linear and nonlinear analysis of cylindrical shells. Eng Struct 25(6):769-778

Djoudi MS, Bahai H (2004a) A cylindrical strain-based shell element for vibration analysis of shell structures. Finite Elem Anal Des 40(13):1947-1961

Djoudi MS, Bahai H (2004b) Strain-based finite element for the vibration of cylindrical panels with openings. Thin Wall Struct 42(4):575-588

Guerraiche K, Belounar L, Bouzidi L (2018) A new eight nodes brick finite element based on the strain approach. J Solid Mech 10(1):186-199

Himeur M, Guenfoud M (2011) Bending triangular finite element with a fictitious fourth node based on the strain approach. Eur J Comput Mech 20(7-8):455-485

Kugler S, Fotiu PA, Murin J (2010) A highly efficient membrane finite element with drilling degrees of freedom. Acta Mech 213(3-4):323-348

Li G, Huang LH (2014) A 4-node plane parameterized element based on quadrilateral area coordinate. Eng Mech 31:15-21

MacNeal RH, Harder RL (1985) A proposed standard set of problems to test finite element accuracy. Finite Elem Anal Des 1(1):3-20

MacNeal RH, Harder RL (1988) A refined four-node membrane element with rotational degrees of freedom. Comput Struct 28(1):75-84

Messai A, Belounar L, Merzouki T (2019) Static and free vibration of plates with a strain based brick element. Eur J Comput Mech. https://doi.org/10.1080/17797179.2018.1560845

Paknahad M, Noorzaei J, Jaafar MS, Thanoon Waleed A (2007) Analysis of shear wall structure using optimal membrane triangle element. Finite Elem Anal Des 43(11-12):861-869

Pian TH, Sumihara K (1984) Rational approach for assumed stress finite elements. Int J Numer Methods Eng 20(9):1685-1695
Piltner R, Taylor RL (1999) A systematic construction of B-BAR functions for linear and non-linear mixed-enhanced finite elements for plane elasticity problems. Int J Numer Methods Eng 44(5):615-635

Rebiai C, Belounar L (2013) A new strain based rectangular finite element with drilling rotation for linear and nonlinear analysis. Arch Civ Mech Eng 13(1):72-81

Rebiai C, Belounar L (2014) An effective quadrilateral membrane finite element based on the strain approach. Measurement 50:263-269

Rezaiee-Pajand M, Karkon M (2013) An effective membrane element based on analytical solution. Eur J Mech A/Solids 39:268-279

Sabir AB (1985a) A rectangular and triangular plane elasticity element with drilling degrees of freedom. In: Proceeding of the 2nd International Conference on Variational Methods in Engineering. Southampton University, Springer-Verlag, Berlin, pp 17-25

Sabir AB (1985b) A segmental finite element for general plane elasticity problems in polar coordinates. In: Proceeding of the 8th International Conference Structure Mechanics in Reactor Technology. Belgium

Sabir AB, Lock AC (1972) A curved cylindrical shell finite element. Int J Mech Sci 14(2):125-135

Sabir AB, Moussa AI (1996) Finite element analysis of cylindricalconical storage tanks using strain-based elements. Struct Eng Rev 8(4):367-374

Sabir AB, Moussa AI (1997) Analysis of fluted conical shell roofs using the finite element method. Comput Struct 64(1-4):239-251

Sze KY, Chen W, Cheung YK (1992) An efficient quadrilateral plane element with drilling degrees of freedom using orthogonal stress modes. Comput Struct 42(5):695-705

Wang C, Qi Z, Zhang X, Hu P (2014) Quadrilateral 4-node quasiconforming plane element with internal parameters. Chin J Theor Appl Mech 46(6):971-976

Xia Y, Zheng G, Hu P (2017) Incompatible modes with Cartesian coordinates and application in quadrilateral finite element formulation. Comput Appl Math 36(2):859-875

Yanus SM, Saigal S, Cook RD (1989) On improved hybrid finite element with rotational degrees of freedom. Int J Numer Methods Eng 28(4):785-800

Zouari W, Hammadi F, Ayad R (2016) Quadrilateral membrane finite elements with rotational DOFs for the analysis of geometrically linear and nonlinear plane problems. Comput Struct 173:139-149

Publisher's Note Springer Nature remains neutral with regard to jurisdictional claims in published maps and institutional affiliations. 